\section{OPEN ACCESS}

Edited by:

Justin Dean,

University of Auckland, New Zealand

Reviewed by:

Angela Leigh Cumberland, RMIT University, Australia

Rachel Anne Hill,

Monash University, Australia

*Correspondence:

Veronique Miron

V.Miron@ed.ac.uk

veronique.miron@ed.ac.uk

Specialty section:

This article was submitted to Embryonic and Developmental Physiology,

a section of the journal

Frontiers in Physiology

Received: 02 July 2018

Accepted: 29 August 2018 Published: 12 September 2018

Citation:

Boardman JP, Ireland G, Sullivan G, Pataky R, Fleiss B, Gressens $P$ and Miron V (2018) The Cerebrospinal Fluid Inflammatory Response to Preterm Birth. Front. Physiol. 9:1299. doi: 10.3389/fphys.2018.01299

\title{
The Cerebrospinal Fluid Inflammatory Response to Preterm Birth
}

\begin{abstract}
James P. Boardman ${ }^{1,2}$, Graeme Ireland ${ }^{1}$, Gemma Sullivan ${ }^{1}$, Rozalia Pataky ${ }^{1}$, Bobbi Fleiss ${ }^{3,4,5}$, Pierre Gressens ${ }^{3,4,5}$ and Veronique Miron ${ }^{1 *}$
\end{abstract}

${ }^{1}$ MRC Centre for Reproductive Health, The Queen's Medical Research Institute, The University of Edinburgh, Edinburgh, United Kingdom, ${ }^{2}$ Centre for Clinical Brain Sciences, Chancellor's Building, The University of Edinburgh, Edinburgh, United Kingdom, ${ }^{3}$ Centre for the Developing Brain, Division of Imaging Sciences and Biomedical Engineering, King's College London, London, United Kingdom, ${ }^{4}$ PROTECT, INSERM, Université Paris Diderot, Sorbonne Paris Cité, Paris, France,

${ }^{5}$ PremUP, Paris, France

Background: Preterm birth is the leading risk factor for perinatal white matter injury, which can lead to motor and neuropsychiatric impairment across the life course. There is an unmet clinical need for therapeutics. White matter injury is associated with an altered inflammatory response in the brain, primarily led by microglia, and subsequent hypomyelination. However, microglia can release both damaging and trophic factors in response to injury, and a comprehensive assessment of these factors in the preterm central nervous system (CNS) has not been carried out.

Method: A custom antibody array was used to assess relative levels of 50 inflammationand myelination-associated proteins in the cerebrospinal fluid (CSF) of preterm infants in comparison to term controls.

Results: Fifteen proteins differed between the groups: BDNF, BTC, C5a, FasL, Follistatin, IL-1 $\beta, \quad I L-2, I L-4, I L-9, I L-17 A, M I P-1 \alpha, M M P 8$, SPP1, TGF $\beta$, and TNF $\beta$ $(p<0.05)$. To investigate the temporal regulation of these proteins after injury, we mined a gene expression dataset of microglia isolated from a mouse model of developmental white matter injury. Microglia in the experimental model showed dynamic temporal expression of genes encoding these proteins, with an initial and sustained pro-inflammatory response followed by a delayed anti-inflammatory response, and a continuous expression of genes predicted to inhibit healthy myelination.

Conclusion: Preterm CSF shows a distinct neuroinflammatory profile compared to term controls, suggestive of a complex neural environment with concurrent damaging and reparative signals. We propose that limitation of pro-inflammatory responses, which occur early after perinatal insult, may prevent expression of myelination-suppressive genes and support healthy white matter development.

Keywords: preterm birth, brain injury, inflammation, cerebrospinal fluid, microglia, myelination

\section{INTRODUCTION}

Preterm birth is closely associated with white matter injury and life course impairments including cerebral palsy, learning difficulty, autism spectrum disorder, and psychiatric disease (Volpe, 2009; Johnson and Marlow, 2017). A characteristic feature of white matter injury is oligodendrocyte dysmaturation, which is driven in part by immune dysregulation, and 
results in hypomyelination (Back and Miller, 2014; Hagberg et al., 2015). Magnetic resonance imaging studies show that generalized atypical white matter tract development is often apparent in preterm infants at term-equivalent age (Batalle et al., 2017; Telford et al., 2017), which suggests that interventions to prevent injury and support normal myelination may need to be applied during the perinatal period. Therefore a priority is to better understand the immune mediators and receptors that drive preterm white matter injury in order to identify therapeutic targets that promote healthy white matter development.

Neuropathological analyses of post-mortem tissue have shown robust activation of central nervous system (CNS)-endogenous immune cells, microglia, which express pro-inflammatory markers (iNOS, TNF $\alpha$, IL-1 $\beta$, and IL-6) (Yoon et al., 1997; Haynes et al., 2009); and systemic inflammation due to comorbidities of preterm birth such as chorioamnionitis and necrotizing enterocolitis, is associated with abnormal white matter on magnetic resonance imaging in vivo (Shah et al., 2008; Anblagan et al., 2016; Barnett et al., 2018).

Elevated levels of inflammatory proteins in blood or cerebrospinal fluid (CSF) are associated with perinatal brain injury and increased risk of adverse neurodevelopmental outcome (Yoon et al., 1996; Nelson et al., 1998; Savman et al., 1998; Bartha et al., 2004; Viscardi et al., 2004; Carlo et al., 2011; Armstrong-Wells et al., 2015; Basu et al., 2015). However, protein levels in plasma do not always correlate with those in the CSF in preterm infants with white matter injury, demonstrating that blood analyses may not reflect events in the CNS (Ellison et al., 2005; Rajkumar et al., 2018). Furthermore, a comprehensive assessment of inflammation-associated factors in preterm CSF has not been carried out. Here, we asked whether a largescale measurement of inflammatory markers in preterm CSF, including measures of factors known to be detrimental or supportive of white matter development, could provide a broader understanding of the neuropathology of preterm brain injury.

\section{MATERIALS AND METHODS}

\section{Participants}

We recruited two groups of neonates from the Royal Infirmary of Edinburgh between June 2014 and September 2015 who required CSF sampling, usually for the evaluation of suspected meningitis: 17 preterm neonates with mean (SD) postmenstrual age (PMA) at birth 27.14 (2.14) weeks; and 20 term infants with mean (SD) PMA at birth 39.86 (1.86) weeks. The mean (SD) PMA at CSF sampling was 29.29 (2.86) weeks for preterm infants and 40.29 (2.0) weeks for term infants. There were no significant differences in the proportion of infants with CSF contaminated by blood defined as red blood cell count $>1000$ cells $/ \mathrm{mm}^{3}$ (50\% versus $42 \%, p=0.73$ ). Methods for sampling and storage of CSF, and the clinical phenotype of participants including plasma C-Reactive Protein, full blood count, CSF total protein and glucose concentrations and CSF microscopy have been reported previously (Pataky et al., 2017). No infant in either group had meningitis; 10 out of 17 of the preterm infants and 8 out of 20 of the term infants were classified as having blood stream infection (BSI) at the time of CSF sampling, defined as either (1) blood culture grew a pathogenic bacterial species; or (2) the blood culture was negative or grew coagulase negative Staphylococcus (CoNS) and the infant had one or more signs of generalized infection (apnoea, temperature instability, feeding intolerance, worsening respiratory distress, or hemodynamic instability) and the attending neonatologist treated with IV antibiotics for $\geq 5$ days. The difference in proportion of infants with BSI in each group was not statistically significant $(p=0.33)$.

This study was carried out in accordance with the recommendations of UK National Research Ethics Service with written informed consent from all subjects. All subjects gave written informed consent in accordance with the Declaration of Helsinki. The protocol was approved by the South East Scotland Research Ethics Committee (14/SS/044). Written parental informed consent was obtained for CSF sampling, and the study was approved by the UK National Research Ethics Service (14/SS/044).

\section{Custom Antibody Microarray}

A custom antibody array ("G-series" from Tebu-bio/RayBiotech) against 50 human analytes was generated to detect relative levels of: activin-A (INHBA), Brain-derived neurotrophic factor (BDNF), bone morphogenetic protein (BMP)2, BMP4, BMP7, betacellulin (BTC), cluster of differentiation (CD)200, Complement 5a (C5a), C-reactive protein (CRP), Fas ligand (FasL), follistatin, furin, Galectin-3 (Gal3), granulocyte macrophage colony-stimulating factor (GM-CSF), insulin-like growth factor-1 (IGF-1), interferon-gamma (IFN $\gamma$ ), insulin, interleukin (IL)-1 $\alpha$, IL-1 $\beta$, IL-2, IL-4, IL-5, IL-6, IL-8, IL-9, IL-10, IL-12p40, IL-12p70, IL-13, IL-17A, IL-17B, IL-17C, IL-17F, IL-18, monocyte chemoattractant protein-1 (MCP1), macrophage inflammatory protein 1-alpha $(M I P 1 \alpha), M I P 1 \beta$, matrix metalloproteinase (MMP) 8, MMP-9, nerve growth factor (NGF)- $\beta$, neurotrophic factor 3 (NT3), Osteopontin (SPP1), placental growth factor (PLGF), regulated on activation, normal $\mathrm{t}$ cell expressed and secreted (RANTES), stem cell factor (SCF), tumor necrosis factor (TNF)- $\alpha$, TNF $\beta$, transforming growth factor-beta (TGF $\beta$ ), urokinase-type plasminogen-activator (uPA), vascular endothelial growth factor-C (VEGF-C). Arrays were carried out according to the manufacturer's instructions. Briefly, antibodies printed onto sub-arrays were dried at room temperature (RT) for $2 \mathrm{~h}$, then blocked for $30 \mathrm{~min}$. Fifty microliters of CSF from each case was incubated with one sub-array for $2 \mathrm{~h}$ at RT, then washed with gentle rocking. Subarrays were then incubated with biotin-conjugated sandwich antibodies for $2 \mathrm{~h}$ at RT, washed thoroughly, then incubated with streptavidin-Cy3. Following washes in water, slides were read at $532 \mathrm{~nm}$ excitation frequency.

\section{Antibody Array Data Analysis}

Detected values of Cy3 intensity were normalized to an internal median background level on each slide. Analytes of interest were defined as those where the median value of the preterm group was outside the interquartile range of the controls. For analyses designed to generate hypotheses about group differences 
for gene expression studies, the distribution of values according to gestation category (preterm versus term) was investigated using independent samples Mann-Whitney $U$ test, individual test $p$-values are reported, and a threshold of $<0.05$ was used to select proteins for microglia gene expression analysis. Analyses were performed using SPSS 21.0 (SPSS Inc., Chicago, IL, United States).

\section{Animal Protocol}

Experimental protocols were approved by the Bichat-Robert Debre (France) ethical committee under the reference 201114/676-0053, and met the guidelines for the United States Public Health Service's Policy on Humane Care and Use of Laboratory Animals (NIH, Bethesda, MD, United States). We housed the OF1 strain mice (Charles River; L'Arbresle, France) under a $12 \mathrm{~h}$ light-dark cycle with ad libitum food and water. On P1 pups were sexed, all males were kept but litters were maintained at 9-11 pups. Assessments of injury and outcomes were made only in male animals as females do not display white matter injury in response to this paradigm. The preponderance to injury in males is similar to what is observed in preterm born infants (O'Driscoll et al., 2018). Neonatal received twice a day (bid) from $\mathrm{P} 1$ to $\mathrm{P} 4$ and once on $\mathrm{P} 5$ a $5 \mu \mathrm{l}$ intra-peritoneal (ip) injection of $10 \mu \mathrm{g} / \mathrm{kg} /$ injection recombinant mouse IL-1 $\beta$ in phosphate buffered saline (PBS; R\&D Systems, Minneapolis, MN, United States) or PBS alone (control). IL-1 $\beta$ exposure, as reported previously, sets up a complex systemic inflammatory response (Favrais et al., 2011) and then a complex central neuroinflammatory response (Krishnan et al., 2017; Van Steenwinckel et al., 2018). This leads to microgliosis, oligodendrocyte maturation arrest, hypomyelination and cognitive deficits (Favrais et al., 2011; Schang et al., 2014; Krishnan et al., 2017; Van Steenwinckel et al., 2018) reminiscent of what is observed in preterm born infants (Billiards et al., 2008; Verney et al., 2012; Caldinelli et al., 2017; Spittle et al., 2017).

\section{Neural Tissue Dissociation and Magnetic-Activated Cell Sorting}

At P1, P5, and P10, we collected brains for cell dissociation and CD11b-positive cell enrichment using a magnetic coupled antibody extraction technique (MACS), as previously described (Schang et al., 2014; Krishnan et al., 2017) and according to the manufacturer's protocol (Miltenyi Biotec, Bergisch Gladbach, Germany). In brief, we pooled brains ( $n=4$ at P1, $n=3$ at P5, and $n=2$ at P10) and after removing the cerebellum and olfactory bulbs they were dissociated using the Neural Tissue Dissociation Kit. A total of six samples per group and per time point were generated with at least four independent litters per group. Using anti-CD11b MicroBeads we captured the $\mathrm{CD} 11 \mathrm{~b}+$ cells and after elution, we centrifuged the isolated cells for $5 \mathrm{~min}$ at $600 \mathrm{~g}$ and then conserved them at $-80^{\circ} \mathrm{C}$. The purity of MACSed CD11B + fraction has been validated using FACS analysis of CD11B fluorescence, and with RT-qPCR of the positive and negative cell fractions as previously described (Schang et al., 2014; Krishnan et al., 2017) and revealed the negative fraction has gene expression levels 98\% lower than found in the respective primary cultures of astrocytes, neurons, and oligodendrocytes.

\section{Microarray Analysis}

As previously published, Miltenyi Biotec (France) performed microarrays (Mouse Agilent Whole Mouse Genome Oligo Microarrays, $8 \times 60 \mathrm{~K}$ ) on 6 samples per time point per group for CD11b enriched cell samples from P1, P5, and P10 mice exposed to IL-1 $\beta$ or PBS; a total of 24 samples (Krishnan et al., 2017). Preparation of samples for array analysis has been previously described (Husson et al., 2005; Chhor et al., 2013; Krishnan et al., 2017). The Agilent feature extraction software was used to process microarray image files. We only included signal intensities above background. Signal intensity values were background subtracted and uploaded following instructions by Miltenyi Biotec GmbH (Stefan Tomiuk) and PerkinElmer (Matt Hudson) into GeneSifter Analysis Edition $\mathrm{v}^{2} .0^{1}$ for further analysis as previously described (Gustavsson et al., 2007). The pre-processed signal intensity values were median normalized, and the gene expression in neuroinflammatory and PBS controls were compared at P1, P5, and P10 using $t$-test $(p<0.05)$ with Benjamini-Hochberg multiple testing correction.

\section{RESULTS}

\section{Differential Levels of Inflammation-Associated Proteins in Pre-term vs. Term Infant Cerebrospinal Fluid}

To conduct a comprehensive assessment of CNS inflammatory state in preterm infants and associate this with factors affecting myelination, we designed an antibody array assessing expression of 50 proteins with functions in regulating inflammation and myelination (Table 1). This approach was optimal to assess relative protein levels in neonatal CSF because it allowed highcontent simultaneous screening of low volumes of fluid with high sensitivity and a broad range of detection.

We found that 28 protein levels had a median value in CSF from preterm infants that was outside the interquartile range of the controls (Table 1, bold type); these represented proteins with known functions in enhancing or resolving inflammation, as well impairing or supporting myelination (Table 1). The distribution of 15 proteins differed in preterm CSF from that of the controls ( $p$-value $<0.05)$, and 5 analytes were increased in preterm CSF at a threshold of $p<0.01$ : C5a, interleukin (IL)-9, osteopontin (SPP1), Fas ligand (FasL), and follistatin. These data demonstrate that preterm CSF has a distinct inflammatory profile compared to term controls that includes both pro-inflammatory and antiinflammatory proteins, as well as those which can support or impair myelination.

\footnotetext{
${ }^{1}$ http://jhu.genesifter.net/login
} 
TABLE 1 | Median (IQR) normalized fluorescence intensity of 50 cerebrospinal fluid analytes from term control infants and preterm infants.

\begin{tabular}{|c|c|c|c|c|c|c|c|}
\hline \multirow[t]{2}{*}{ Analyte } & \multirow[t]{2}{*}{ Function } & \multicolumn{3}{|c|}{ Control } & \multicolumn{2}{|c|}{ Preterm } & \multirow[t]{2}{*}{$p$-Value } \\
\hline & & Median & IQR & Q1-Q3 & Median & IQR & \\
\hline C5a $(H c)$ & $\odot$ & 1378.5 & 1382.5 & 680.8-2063.3 & 3592.6 & 2540.3 & $0.001^{* *}$ \\
\hline CRP & $\odot$ & 28446.4 & 20206.4 & 15120.2-35326.6 & 35217.1 & 18532.5 & 0.133 \\
\hline GM-CSF (Csf2) & $\odot$ & 255.6 & 91.2 & $212.2-303.5$ & 330.2 & 284.2 & 0.125 \\
\hline $\mathrm{IFN} \gamma$ & $\odot \circ$ & 403.2 & 127.0 & $328.4-455.4$ & 402.4 & 159.3 & 0.916 \\
\hline IL-1 $\alpha$ & $\odot$ & 490.5 & 81.4 & $450.6-532.0$ & 581.9 & 546.13 & 0.220 \\
\hline IL-1 $\beta$ & $\odot ०$ & 52.1 & 73.3 & $10.0-83.3$ & 108.8 & 338.8 & $0.014^{*}$ \\
\hline IL-2 & $\odot$ & 413.1 & 77.8 & $367.7-445.5$ & 520.5 & 298.0 & $0.030^{*}$ \\
\hline IL-6 & $\odot \square$ & 580.0 & 3259.5 & $413.8-3673.3$ & 706.2 & 8133.4 & 0.869 \\
\hline IL-8 & $\odot$ & 19466.8 & 55521.7 & $16192.7-71714.4$ & 18370.4 & 79637.3 & 0.707 \\
\hline IL-9 & $\odot \circ$ & 188.8 & 76.1 & $136.9-213.1$ & 242.6 & 233.23 & $0.005^{* *}$ \\
\hline IL-12p40 & $\odot$ & 62.5 & 87.3 & $22.8-110.1$ & 83.3 & 206.6 & 0.167 \\
\hline IL-12p70 & $\odot$ & 164.3 & 80.0 & $110.1-190.0$ & 220.1 & 219.8 & 0.177 \\
\hline IL-17A & $\odot \mathbf{a}$ & 202.1 & 45.4 & $182.5-227.9$ & 296.4 & 225.6 & $0.028^{*}$ \\
\hline IL-17B & $\odot$ & 104.6 & 20.0 & $96.3-116.3$ & 107.0 & 125.4 & 0.798 \\
\hline IL-17C & $\odot$ & 508.8 & 99.8 & $456.7-556.5$ & 546.2 & 246.9 & 0.052 \\
\hline IL-17F & $\odot$ & 72.5 & 73.2 & $22.8-96.0$ & 62.6 & 214.0 & 0.619 \\
\hline IL-18 & $\odot$ & 80.9 & 49.6 & $50.0-81.0$ & 101.8 & 129.0 & 0.326 \\
\hline MCP-1 (Ccl2) & $\odot$ & 116104.0 & 10004.9 & $112697.7-122702.6$ & 109752.5 & 40956.0 & 0.283 \\
\hline $\mathrm{MIP} 1 \alpha(\mathrm{Ccl} 3)$ & $\odot$ & 211.5 & 282.6 & $118.0-400.6$ & 1054.5 & 4168.5 & $0.015^{*}$ \\
\hline MIP1 $\beta$ (Ccl4) & $\odot$ & 6715.4 & 17113.7 & $5549.0-22562.7$ & 26868.7 & 31793.7 & 0.133 \\
\hline PIGF & $\odot$ & 593.2 & 375.6 & 438.0-813.6 & 948.0 & 1180.7 & 0.056 \\
\hline RANTES & $\odot$ & 182.8 & 1590.6 & $115.7-1706.3$ & 736.4 & 14673.8 & 0.244 \\
\hline $\mathrm{TNF} \alpha$ & $\odot \square$ & 1095.9 & 167.4 & $1036.8-1204.2$ & 1242.3 & 935.8 & 0.074 \\
\hline TNF $\beta$ & $\odot$ & 452.6 & 68.8 & 404.4-473.3 & 504.0 & 380.4 & $0.011^{*}$ \\
\hline UPA & $\odot$ & 8733.4 & 8969.4 & $4470.1-13439.5$ & 12527.5 & 18004.0 & 0.149 \\
\hline CD200 & $\diamond$ & 98.9 & 61.3 & $58.4-119.7$ & 113.6 & 163.9 & 0.326 \\
\hline IL-4 & $\diamond$ & 402.7 & 80.7 & $340.7-421.4$ & 430.6 & 176.6 & $0.042^{*}$ \\
\hline IL-5 & $\bullet$ & 299.9 & 58.6 & $271.5-330.1$ & 301.9 & 258.2 & 0.798 \\
\hline IL-10 & $\Delta \square$ & 481.6 & 787.9 & $429.1-1216.9$ & 917.7 & 6406.5 & 0.341 \\
\hline IL-13 & $\bullet$ & 382.8 & 93.4 & $336.2-429.5$ & 416.3 & 330.8 & 0.104 \\
\hline Activin-A (INHBA) & $\boldsymbol{\nabla}$ & 238.2 & 62.7 & 204.9-267.6 & 271.1 & 314.6 & 0.257 \\
\hline BDNF & $\mathbf{\square}$ & 101.6 & 18.6 & $95.3-113.9$ & 145.8 & 191.5 & $0.024^{*}$ \\
\hline ВтC & $\square$ & 304.7 & 49.3 & $273.3-322.6$ & 354.0 & 256.7 & $0.045^{*}$ \\
\hline$\beta$-NGF & $\mathbf{\square}$ & 206.4 & 169.2 & 119.1-288.2 & 339.6 & 550.56 & 0.117 \\
\hline NT-3 & $\square$ & 85.7 & 55.20 & 49.9-105.1 & 106.7 & 147.0 & 0.283 \\
\hline Furin & $\square$ & 360.4 & 580.5 & 189.6-770.1 & 464.7 & 995.9 & 0.537 \\
\hline Galectin-3 & $\mathbf{\square}$ & 1598.1 & 1419.0 & $859.2-2278.2$ & 1069.9 & 4638.26 & 0.892 \\
\hline IGF-1 & $\mathbf{\square}$ & 2005.4 & 574.4 & 1685.3-2259.6 & 2048.0 & 662.5 & 0.812 \\
\hline Insulin (Ins1) & $\square$ & 180.6 & 70.3 & $149.0-219.3$ & 253.8 & 271.8 & 0.074 \\
\hline SCF (Kitl) & $\square$ & 346.7 & 287.7 & 230.9-518.6 & 419.4 & 631.8 & 0.326 \\
\hline SPP1 & $\square$ & 1209.4 & 1828.0 & $766.5-2594.4$ & 3064.4 & 4333.1 & $0.007^{* *}$ \\
\hline TGF $\beta$ & $\boldsymbol{\square}$ & 706.2 & 122.0 & $640.7-762.7$ & 919.0 & 600.0 & $0.013^{*}$ \\
\hline VEGF-C & $\square$ & 250.6 & 100.1 & 209.6-309.7 & 233.7 & 312.5 & 0.641 \\
\hline BMP2 & 0 & 191.5 & 168.6 & $100.5-269.1$ & 140.3 & 301.7 & 0.752 \\
\hline BMP4 & 0 & 116.1 & 90.1 & $72.4-162.5$ & 106.0 & 173.1 & 0.845 \\
\hline BMP7 & 0 & 196.5 & 211.8 & $156.2-232.0$ & 246.0 & 221.5 & 0.104 \\
\hline FasL & 0 & 290.1 & 159.6 & $203.1-362.7$ & 967.0 & 1484.7 & $0.001^{* *}$ \\
\hline Follistatin (Fst) & 0 & 920.6 & 286.0 & $754.3-1040.3$ & 1683.0 & 1192.8 & $0.007^{* *}$ \\
\hline MMP8 & 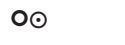 & 319.7 & 187.2 & 219.5-406.7 & 416.7 & 1319.90 & $0.026^{*}$ \\
\hline MMP-9 & $\odot$ & 156.4 & 126.2 & $110.8-237.0$ & 244.8 & 1378.6 & 0.125 \\
\hline
\end{tabular}

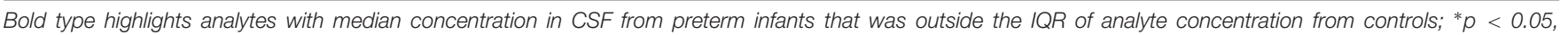

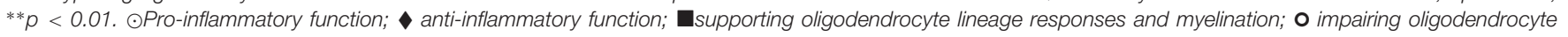
lineage responses and myelination. 


\section{Mapping of Dynamic Regulation of Inflammatory and Myelination-Associated Proteins During Experimental Developmental Brain Injury}

To better understand how the proteins elevated in preterm infant CSF are regulated after injury, we mined an existing dataset in which dynamic changes in microglia gene expression were measured in an experimental model of developmental white matter injury. In this model, damage was induced by intraperitoneal injections of recombinant IL-1 $\beta(10 \mu \mathrm{g} / \mathrm{ml})$ prior to the onset of myelination (twice daily from postnatal day $[\mathrm{P}] 1$ to P4 and one injection at P5) (Figure 1A). This paradigm mimics the pathophysiology of human perinatal brain injury by chronically impairing oligodendrocyte differentiation and myelination, as evidenced by immunostaining of myelin proteins, the oligodendrocyte lineage and electron microscopy (Favrais et al., 2011; Krishnan et al., 2017).

We analyzed microglia gene expression at the time of inflammation initiation (P1), during the subsequent phase when oligodendrocyte differentiation is impaired (P5), and when hypomyelination is observed (P10). Eleven of 15 proteins we found to be altered in human preterm CSF were significantly regulated at the mRNA level by microglia during the course of white matter injury (Figure 1B). At P1, microglia from IL-1 $\beta$-treated mice showed an upregulation of pro-inflammatory genes $I l 1 b$ and Tnf and concomitant downregulation of anti-inflammatory gene Il4 (Figure 1C). Tgfbl, which supports oligodendrocyte lineage survival, proliferation, and differentiation (Dutta et al., 2014; Palazuelos et al., 2014), was upregulated simultaneously with $M m p 8$, which is associated with myelin damage (Folgueras et al., 2008; Figure 1C). At P5, microglia upregulated pro-inflammatory genes C5a $(H c)$, $I l 1 b$, Il2, Ill7a, and showed a sustained downregulation of Il4 (Figure 1D). Also upregulated were genes predicted to inhibit oligodendrocyte health and differentiation: $M m p 8$ (Folgueras et al., 2008), Fasl (associated with oligodendrocyte death) (Wosik et al., 2003), and Fst (which would inhibit activin-A-driven oligodendrocyte differentiation) (Dillenburg et al., 2018; Figure 1D). At P10, Il1b, Tnf, and Fasl were still upregulated, however, concomitant upregulation of Il4 and pro-myelination gene Spp1 (Osteopontin) may indicate late attempts to resolve inflammation and counter white matter damage (Figure 1E). Illb and Il4, prototypical pro- and antiinflammatory cytokines respectively, were found to be regulated in expression throughout injury, with a sustained upregulation of $I l 1 b$ and a delayed $I l 4$ response (Figure 1F). With regards to genes regulating myelination, although pro-survival/myelination genes $T g f b 1$ and $S p p 1$ were slightly upregulated early and late in injury, respectively, genes whose products are predicted to impair white matter health were upregulated at all time points (Figure 1G). This data suggest that the proteins enriched in human preterm CSF are dynamically expressed by microglia following developing white matter insult, with an initial and sustained pro-inflammatory response followed by a delayed anti-inflammatory response, and a continuous expression of genes predicted to inhibit healthy myelination.

\section{DISCUSSION}

In this study, we identified a distinct inflammatory signature in preterm CSF relative to term controls. A comprehensive and sensitive measure of CSF protein levels by antibody array identified 15 factors which were relatively increased in preterm samples, and which have been previously associated with regulating inflammation and myelination. This revealed a complex preterm neural environment, with concurrent proand anti-inflammatory responses, and pro- and anti-myelination factors. Data-mining of microglia transcriptomes in the context of experimental perinatal brain injury revealed that microglia can express the majority of these factors following insult, and they are dynamically regulated over time, mirroring the complexity of inflammatory and myelination-regulating factors measured in the human samples. Although some of these genes are expressed by microglia in healthy developing brain (Il1b, Ccl3, Tnf, Spp1, and $\mathrm{Tgfb1}$ ) (Zhang et al., 2014), the rapid increase of proinflammatory gene expression in microglia in this experimental model shortly after the first injection of IL-1 $\beta$, concomitant with sustained expression of genes predicted to impair myelination, highlight the importance of early intervention to limit damage to the developing white matter.

Five proteins were increased in preterm CSF vs. controls at the threshold $p<0.01$ : C5a, IL-9, SPP1, FasL, and Follistatin. C5a is a component of the complement cascade which we previously showed to be increased in human preterm CSF by enzyme-linked immunoabsorbant assay (Pataky et al., 2017), validating our novel approach of using antibody array to identify differentially expressed proteins in CSF samples. Although C5a has been associated with normal brain development (Benard et al., 2008) and neuroprotection (Biggins et al., 2017), it may have damaging functions as inhibition of its receptor $\mathrm{C} 5 \mathrm{aR}$ attenuates excitotoxic perinatal brain injury (Pedroni et al., 2013) and $\mathrm{C} 5 \mathrm{a}$ is increased in the CSF of children with demyelinating disease (Horellou et al., 2015). In addition, we identified IL-9 as a novel preterm birth-associated CNS cytokine in humans. Although we found it is not regulated by microglia in the IL$1 \beta$ injury model, it may be expressed by other cell types such as Th9 lymphocytes. In experimental models it has roles in mast cell activation and excitotoxicity (Patkai et al., 2001), neonatal cortical neuronal apoptosis (Fontaine et al., 2008), autoimmune demyelination ( $\mathrm{Li}$ et al., 2011), and regulation of astrocyte chemokine production (Ding et al., 2015); our data support a role for IL9 in the human inflammatory response to preterm birth. In addition, its expression can be driven by TGF $\beta$ (Beriou et al., 2010), which when overexpressed by microglia is associated with hypomyelination (Nobuta et al., 2012). IL-9 may also have direct actions on oligodendrocyte lineage cells, as these express the IL-9 receptor and IL-9 treatment inhibits their differentiation in vitro, although, notably, it can encourage differentiation if co-supplied with IFN- $\gamma$ (Ding et al., 2015).

The remaining three highly enriched proteins have been implicated in regulating the oligodendrocyte lineage and myelination. Osteopontin (SPP1) in particular has been suggested as a blood biomarker for neonatal encephalopathy (Graham et al., 2018) and it is highly induced by hypoxic 


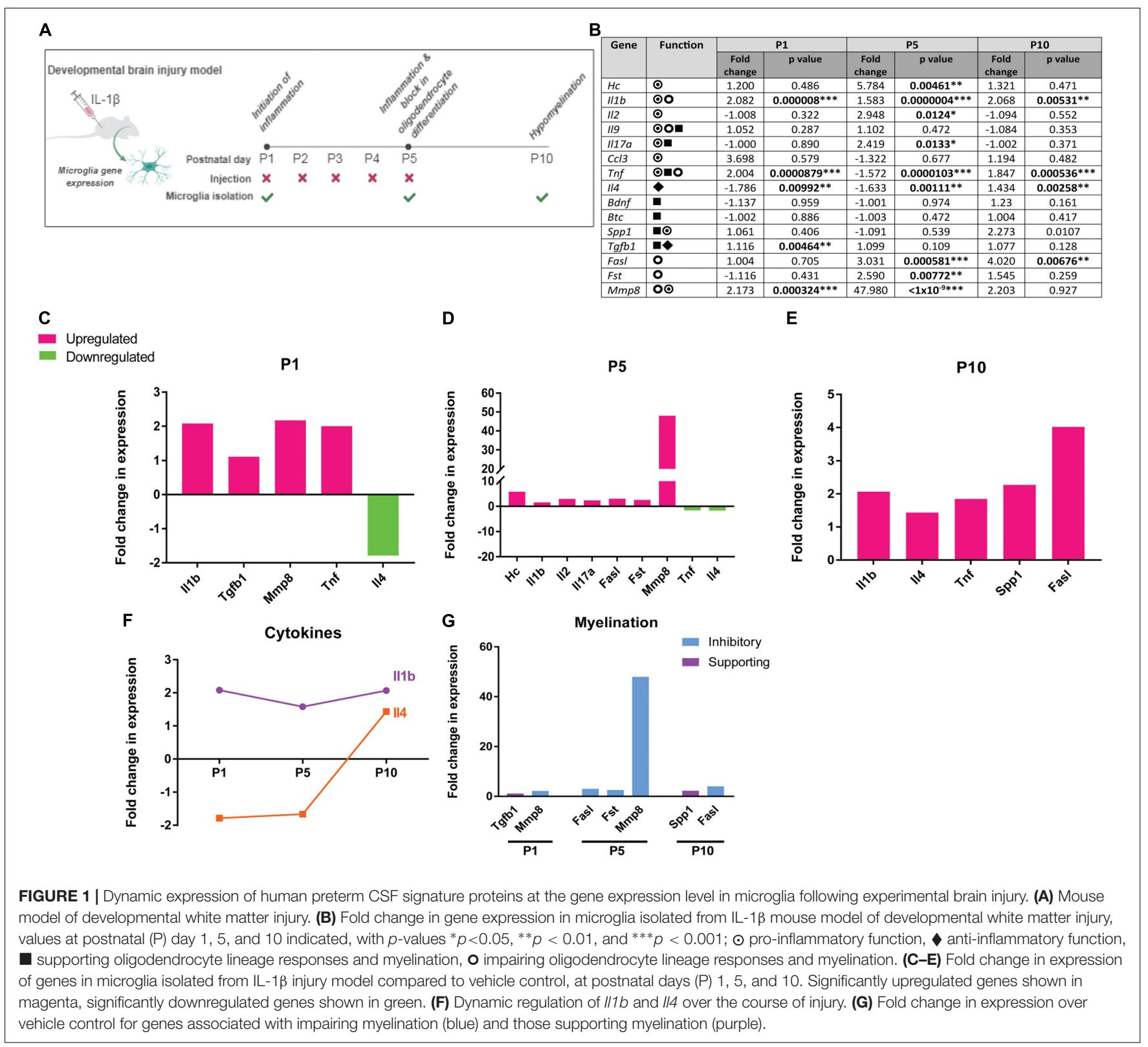

injury, where a protective role is suggested by decreased oligodendrogenesis in a knockout mouse subjected to hypoxicischemic injury (van Velthoven et al., 2011). This beneficial role may be dependent on mode of neural injury or age, as in adult mice SPP1 exacerbates autoimmune-mediated demyelination and is not required for regeneration of myelin on previously myelinated axons (Zhao et al., 2008). Nonetheless, it can directly increase myelin protein expression and myelination in vitro (Selvaraju et al., 2004). Another protein we detected in preterm CSF which may directly modulate myelination is follistatin, which sequesters activin-A to prevent its binding to activin receptors. This would be predicted to impair myelination, as we have recently shown these receptors to be required for oligodendrocyte differentiation and myelin maturation in healthy white matter development and following injury
(Dillenburg et al., 2018). Lastly, the increase in Fas ligand in preterm CSF may indicate direct targeting of oligodendrocytes, as it has been associated with induction of oligodendrocyte death in a variety of neurological disorders (Austin and Fehlings, 2008).

Our study has some limitations. Although no infant in the study group had meningitis, a proportion of preterm and term infants had BSI at the time of CSF sampling. Therefore, it is possible that systemic inflammation contributed to observed alterations in the CSF inflammatory profile, although this potential confounding effect is likely to be balanced across the groups.

Our study was not designed to investigate the effect of astrocyte-mediated cytokine production, which could contribute to neuroinflammation as has been suggested by some experimental perinatal white matter injury models 
(Nobuta et al., 2012; Shiow et al., 2017). In future work, investigating gene expression in other cell types including astrocytes and neurones may be informative.

Altogether, these findings identify a CSF signature in response to preterm birth, which reflects a complex environment that can both drive injury and support myelination. The pathological outcome of preterm birth may thus reflect a balance between damaging and reparative factors, which implies that effective therapies may need to operate on multiple targets. We propose that early therapeutic intervention could pre-empt the robust pro-inflammatory response and boost pro-repair mechanisms to support healthy myelination.

\section{DATA AVAILABILITY}

All human CSF data generated or analyzed during this study are included in this published article. The microglia gene expression datasets analyzed during the current study are available from the corresponding author on reasonable request.

\section{AUTHOR CONTRIBUTIONS}

JB co-designed the study, analyzed the patient data, and contributed to writing the manuscript. GI and GS analyzed

\section{REFERENCES}

Anblagan, D., Pataky, R., Evans, M. J., Telford, E. J., Serag, A., Sparrow, S., et al. (2016). Association between preterm brain injury and exposure to chorioamnionitis during fetal life. Sci. Rep. 6:37932. doi: 10.1038/srep 37932

Armstrong-Wells, J., Donnelly, M., Post, M. D., Manco-Johnson, M. J., Winn, V. D., and Sébire, G. (2015). Inflammatory predictors of neurologic disability after preterm premature rupture of membranes. Am. J. Obstet. Gynecol. 212, 212.e1-212.e9. doi: 10.1016/j.ajog.2014.09.016

Austin, J. W., and Fehlings, M. G. (2008). Molecular mechanisms of fas-mediated cell death in oligodendrocytes. J. Neurotrauma 25, 411-426. doi: 10.1089/neu. 2007.0436

Back, S. A., and Miller, S. P. (2014). Brain injury in premature neonates: a primary cerebral dysmaturation disorder? Ann. Neurol. 75, 469-486. doi: 10.1002/ana. 24132

Barnett, M. L., Tusor, N., Ball, G., Chew, A., Falconer, S., Aljabar, P., et al. (2018). Exploring the multiple-hit hypothesis of preterm white matter damage using diffusion MRI. Neuroimage Clin. 17, 596-606. doi: 10.1016/j.nicl.2017.11.017

Bartha, A. I., Foster-Barber, A., Miller, S. P., Vigneron, D. B., Glidden, D. V., Barkovich, A. J., et al. (2004). Neonatal encephalopathy: association of cytokines with MR spectroscopy and outcome. Pediatr. Res. 56, 960-966. doi: 10.1203/01. Pdr.0000144819.45689.Bb

Basu, S., Agarwal, P., Anupurba, S., Shukla, R., and Kumar, A. (2015). Elevated plasma and cerebrospinal fluid interleukin-1 beta and tumor necrosis factor-alpha concentration and combined outcome of death or abnormal neuroimaging in preterm neonates with early-onset clinical sepsis. J. Perinatol. 35, 855-861. doi: 10.1038/jp.2015.86

Batalle, D., Hughes, E. J., Zhang, H., Tournier, J. D., Tusor, N., Aljabar, P., et al. (2017). Early development of structural networks and the impact of prematurity on brain connectivity. Neuroimage 149, 379-392. doi: 10.1016/j.neuroimage. 2017.01.065

Benard, M., Raoult, E., Vaudry, D., Leprince, J., Falluel-Morel, A., Gonzalez, B. J., et al. (2008). Role of complement anaphylatoxin receptors (C3aR, C5aR) in the development of the rat cerebellum. Mol. Immunol. 45, 3767-3774. doi: 10.1016/j.molimm.2008.05.027 the patient samples. BF and PG co-designed the study, carried out the animal experiments, and generated the microglial gene expression dataset. RP collected the human CSF samples. VM co-designed the study, analyzed the microglia gene expression dataset, and co-wrote the manuscript. All authors read and approved the final manuscript.

\section{FUNDING}

This work was supported by Theirworld (www.theirworld.org), the MRC Centre for Reproductive Health (MRC G1002033), and a Career Development Award from the Medical Research Council (V.E.M.; MR/M020827/1). The funding body had no role in the design of the study or sample collection, analysis, and interpretation of data, or in writing the manuscript.

\section{ACKNOWLEDGMENTS}

The authors are grateful to the parents and carers who consented to take part in the study, and to clinical colleagues at the Neonatal Intensive Care Unit of the Royal Infirmary of Edinburgh for referring patients. The diagram in Figure 1A was created with BioRender.

Beriou, G., Bradshaw, E. M., Lozano, E., Costantino, C. M., Hastings, W. D., Orban, T., et al. (2010). TGF-beta induces IL-9 production from human Th17 cells. J. Immunol. 185, 46-54. doi: 10.4049/jimmunol.10 00356

Biggins, P. J. C., Brennan, F. H., Taylor, S. M., Woodruff, T. M., and Ruitenberg, M. J. (2017). The alternative receptor for complement component 5a, C5aR2, conveys neuroprotection in traumatic spinal cord injury. J. Neurotrauma 34, 2075-2085. doi: 10.1089/neu.2016.4701

Billiards, S. S., Haynes, R. L., Folkerth, R. D., Borenstein, N. S., Trachtenberg, F. L., Rowitch, D. H., et al. (2008). Myelin abnormalities without oligodendrocyte loss in periventricular leukomalacia. Brain Pathol. 18, 153-163. doi: 10.1111/j.17503639.2007.00107.x

Caldinelli, C., Froudist-Walsh, S., Karolis, V., Tseng, C. E., Allin, M. P., Walshe, M., et al. (2017). White matter alterations to cingulum and fornix following very preterm birth and their relationship with cognitive functions. Neuroimage 150, 373-382. doi: 10.1016/j.neuroimage.2017.02.026

Carlo, W. A., McDonald, S. A., Tyson, J. E., Stoll, B. J., Ehrenkranz, R. A., Shankaran, S., et al. (2011). Cytokines and neurodevelopmental outcomes in extremely low birth weight infants. J. Pediatr. 159, 919.e3-925.e3. doi: 10.1016/ j.jpeds.2011.05.042

Chhor, V., Le Charpentier, T., Lebon, S., Oré, M. V., Celador, I. L., Josserand, J., et al. (2013). Characterization of phenotype markers and neuronotoxic potential of polarised primary microglia in vitro. Brain Behav. Immun. 32, 70-85. doi: 10.1016/j.bbi.2013.02.005

Dillenburg, A., Ireland, G., Holloway, R. K., Davies, C. L., Evans, F. L., Swire, M., et al. (2018). Activin receptors regulate the oligodendrocyte lineage in health and disease. Acta Neuropathol. 135, 887-906. doi: 10.1007/s00401-018-1 813-3

Ding, X., Cao, F., Cui, L., Ciric, B., Zhang, G. X., and Rostami, A. (2015). IL-9 signaling affects central nervous system resident cells during inflammatory stimuli. Exp. Mol. Pathol. 99, 570-574. doi: 10.1016/j.yexmp.2015. 07.010

Dutta, D. J., Zameer, A., Mariani, J. N., Zhang, J., Asp, L., Huynh, J., et al. (2014). Combinatorial actions of Tgfbeta and activin ligands promote oligodendrocyte development and CNS myelination. Development 141, 2414-2428. doi: 10.1242/ dev.106492 
Ellison, V. J., Mocatta, T. J., Winterbourn, C. C., Darlow, B. A., Volpe, J. J., and Inder, T. E. (2005). The relationship of CSF and plasma cytokine levels to cerebral white matter injury in the premature newborn. Pediatr. Res. 57, 282-286. doi: 10.1203/01.pdr.0000148286.53572.95

Favrais, G., van de Looij, Y., Fleiss, B., Ramanantsoa, N., Bonnin, P., StoltenburgDidinger, G., et al. (2011). Systemic inflammation disrupts the developmental program of white matter. Ann. Neurol. 70, 550-565. doi: 10.1002/ana. 22489

Folgueras, A. R., Fueyo, A., García-Suárez, O., Cox, J., Astudillo, A., Tortorella, P., et al. (2008). Collagenase-2 deficiency or inhibition impairs experimental autoimmune encephalomyelitis in mice. J. Biol. Chem. 283, 9465-9474. doi: 10.1074/jbc.M709522200

Fontaine, R. H., Cases, O., Lelièvre, V., Mesplès, B., Renauld, J. C., Loron, G., et al. (2008). IL-9/IL-9 receptor signaling selectively protects cortical neurons against developmental apoptosis. Cell Death Differ. 15, 1542-1552. doi: 10.1038/cdd. 2008.79

Graham, E. M., Everett, A. D., Delpech, J. C., and Northington, F. J. (2018). Blood biomarkers for evaluation of perinatal encephalopathy: state of the art. Curr. Opin. Pediatr. 30, 199-203. doi: 10.1097/mop.0000000000000591

Gustavsson, M., Mallard, C., Vannucci, S. J., Wilson, M. A., Johnston, M. V., and Hagberg, H. (2007). Vascular response to hypoxic preconditioning in the immature brain. J. Cereb. Blood Flow Metab. 27, 928-938. doi: 10.1038/sj.jcbfm. 9600408

Hagberg, H., Mallard, C., Ferriero, D. M., Vannucci, S. J., Levison, S. W., Vexler, Z. S., et al. (2015). The role of inflammation in perinatal brain injury. Nat. Rev. Neurol. 11, 192-208. doi: 10.1038/nrneurol.2015.13

Haynes, R. L., Folkerth, R. D., Trachtenberg, F. L., Volpe, J. J., and Kinney, H. C. (2009). Nitrosative stress and inducible nitric oxide synthase expression in periventricular leukomalacia. Acta Neuropathol. 118, 391-399. doi: 10.1007/ s00401-009-0540-1

Horellou, P., Wang, M., Keo, V., Chrétien, P., Serguera, C., Waters, P., et al. (2015). Increased interleukin-6 correlates with myelin oligodendrocyte glycoprotein antibodies in pediatric monophasic demyelinating diseases and multiple sclerosis. J. Neuroimmunol. 289, 1-7. doi: 10.1016/j.jneuroim.2015. 10.002

Husson, I., Rangon, C. M., Lelièvre, V., Bemelmans, A. P., Sachs, P., Mallet, J., et al. (2005). BDNF-induced white matter neuroprotection and stage-dependent neuronal survival following a neonatal excitotoxic challenge. Cereb. Cortex 15, 250-261. doi: 10.1093/cercor/bhh127

Johnson, S., and Marlow, N. (2017). Early and long-term outcome of infants born extremely preterm. Arch. Dis. Child. 102, 97-102. doi: 10.1136/archdischild2015-309581

Krishnan, M. L., Van Steenwinckel, J., Schang, A. L., Yan, J., Arnadottir, J., Le Charpentier, T., et al. (2017). Integrative genomics of microglia implicates DLG4 (PSD95) in the white matter development of preterm infants. Nat. Commun. 8:428. doi: 10.1038/s41467-017-00422-w

Li, H., Nourbakhsh, B., Cullimore, M., Zhang, G. X., and Rostami, A. (2011). IL-9 is important for T-cell activation and differentiation in autoimmune inflammation of the central nervous system. Eur. J. Immunol. 41, 2197-2206. doi: 10.1002/eji.201041125

Nelson, K. B., Dambrosia, J. M., Grether, J. K., and Phillips, T. M. (1998). Neonatal cytokines and coagulation factors in children with cerebral palsy. Ann. Neurol. 44, 665-675. doi: 10.1002/ana.410440413

Nobuta, H., Ghiani, C. A., Paez, P. M., Spreuer, V., Dong, H., Korsak, R. A., et al. (2012). STAT3-mediated astrogliosis protects myelin development in neonatal brain injury. Ann. Neurol. 72, 750-765. doi: 10.1002/ana. 23670

O’Driscoll, D. N., McGovern, M., Greene, C. M., and Molloy, E. J. (2018). Gender disparities in preterm neonatal outcomes. Acta Paediatr. doi: 10.1111/apa.14390 [Epub ahead of print].

Palazuelos, J., Klingener, M., and Aguirre, A. (2014). TGFbeta signaling regulates the timing of CNS myelination by modulating oligodendrocyte progenitor cell cycle exit through SMAD3/4/FoxO1/Sp1. J. Neurosci. 34, 7917-7930. doi: 10.1523/jneurosci.0363-14.2014

Pataky, R., Howie, F. A., Girardi, G., and Boardman, J. P. (2017). Complement C5a is present in CSF of human newborns and is elevated in association with preterm birth. J. Matern. Fetal Neonatal Med. 30, 2413-2416. doi: 10.1080/ 14767058.2016.1251896
Patkai, J., Mesples, B., Dommergues, M. A., Fromont, G., Thornton, E. M., Renauld, J. C., et al. (2001). Deleterious effects of IL-9-activated mast cells and neuroprotection by antihistamine drugs in the developing mouse brain. Pediatr. Res. 50, 222-230. doi: 10.1203/00006450-200108000-200108010

Pedroni, S. M., Gonzalez, J. M., Wade, J., Jansen, M. A., Serio, A., Marshall, I., et al. (2013). Complement inhibition and statins prevent fetal brain cortical abnormalities in a mouse model of preterm birth. Biochim. Biophys. Acta 1842, 107-115. doi: 10.1016/j.bbadis.2013.10.011

Rajkumar, R., Bhaya, B., Mamilla, D., Czech, T., Kisseih, E., Saini, A., et al. (2018). A preliminary evaluation of glial cell line-derived neurotrophic factor (GDNF) levels in cerebrospinal fluid across various gestational ages and clinical conditions of the neonate. Int. J. Dev. Neurosci. 65, 61-65. doi: 10.1016/j. ijdevneu.2017.10.001

Savman, K., Blennow, M., Gustafson, K., Tarkowski, E., and Hagberg, H. (1998). Cytokine response in cerebrospinal fluid after birth asphyxia. Pediatr. Res. 43, 746-751. doi: 10.1203/00006450-199806000-00006

Schang, A. L., Van Steenwinckel, J., Chevenne, D., Alkmark, M., Hagberg, H., Gressens, P., et al. (2014). Failure of thyroid hormone treatment to prevent inflammation-induced white matter injury in the immature brain. Brain. Behav. Immun. 37, 95-102. doi: 10.1016/j.bbi.2013.11.005

Selvaraju, R., Bernasconi, L., Losberger, C., Graber, P., Kadi, L., Avellana-Adalid, V., et al. (2004). Osteopontin is upregulated during in vivo demyelination and remyelination and enhances myelin formation in vitro. Mol. Cell. Neurosci. 25, 707-721. doi: 10.1016/j.mcn.2003.12.014

Shah, D. K., Doyle, L. W., Anderson, P. J., Bear, M., Daley, A. J., Hunt, R. W., et al. (2008). Adverse neurodevelopment in preterm infants with postnatal sepsis or necrotizing enterocolitis is mediated by white matter abnormalities on magnetic resonance imaging at term. J. Pediatr. 153, 170.e1-175.e1. doi: 10.1016/j.jpeds.2008.02.033

Shiow, L. R., Favrais, G., Schirmer, L., Schang, A. L., Cipriani, S., Andres, C., et al. (2017). Reactive astrocyte COX2-PGE2 production inhibits oligodendrocyte maturation in neonatal white matter injury. Glia 65, 2024-2037. doi: 10.1002/ glia.23212

Spittle, A. J., Walsh, J. M., Potter, C., Mcinnes, E., Olsen, J. E., Lee, K. J., et al. (2017) Neurobehaviour at term-equivalent age and neurodevelopmental outcomes at 2 years in infants born moderate-to-late preterm. Dev. Med. Child Neurol. 59, 207-215. doi: 10.1111/dmcn.13297

Telford, E. J., Cox, S. R., Fletcher-Watson, S., Anblagan, D., Sparrow, S., Pataky, R., et al. (2017). A latent measure explains substantial variance in white matter microstructure across the newborn human brain. Brain Struct. Funct. 222, 4023-4033. doi: 10.1007/s00429-017-1455-6

Van Steenwinckel, J., Schang, A. L., Krishnan, M. L., Degos, V., DelahayeDuriez, A., Bokobza, C., et al. (2018). Loss of the Wnt/ $\beta$-catenin pathway in microglia of the developing brain drives pro-inflammatory activation leading to white matter injury. bioRxiv [Preprint]. doi: 10.1101/334359

van Velthoven, C. T., Heijnen, C. J., van Bel, F., and Kavelaars, A. (2011). Osteopontin enhances endogenous repair after neonatal hypoxicischemic brain injury. Stroke 42, 2294-2301. doi: 10.1161/strokeaha.110.60 8315

Verney, C., Pogledic, I., Biran, V., Adle-Biassette, H., Fallet-Bianco, C., and Gressens, P. (2012). Microglial reaction in axonal crossroads is a hallmark of noncystic periventricular white matter injury in very preterm infants. J. Neuropathol. Exp. Neurol. 71, 251-264. doi: 10.1097/NEN.0b013e3182496429

Viscardi, R. M., Muhumuza, C. K., Rodriguez, A., Fairchild, K. D., Sun, C. C., Gross, G. W., et al. (2004). Inflammatory markers in intrauterine and fetal blood and cerebrospinal fluid compartments are associated with adverse pulmonary and neurologic outcomes in preterm infants. Pediatr. Res. 55, 1009-1017. doi: 10.1203/01.pdr.0000127015.60185.8a

Volpe, J. J. (2009). Brain injury in premature infants: a complex amalgam of destructive and developmental disturbances. Lancet Neurol. 8, 110-124. doi: 10.1016/S1474-4422(08)70294-1

Wosik, K., Antel, J., Kuhlmann, T., Brück, W., Massie, B., and Nalbantoglu, J. (2003). Oligodendrocyte injury in multiple sclerosis: a role for p53. J. Neurochem. 85, 635-644. doi: 10.1046/j.1471-4159.2003.01674.x

Yoon, B. H., Romero, R., Kim, C. J., Koo, J. N., Choe, G., Syn, H. C., et al. (1997). High expression of tumor necrosis factor-alpha and interleukin6 in periventricular leukomalacia. Am. J. Obstet. Gynecol. 177, 406-411. doi: 10.1016/S0002-9378(97)70206-0 
Yoon, B. H., Romero, R., Yang, S. H., Jun, J. K., Kim, I. O., Choi, J. H., et al. (1996), Interleukin- 6 concentrations in umbilical cord plasma are elevated in neonates with white matter lesions associated with periventricular leukomalacia. Am. J. Obstet. Gynecol. 174, 1433-1440. doi: 10.1016/S0002-9378(96)70585-9

Zhang, Y., Chen, K., Sloan, S. A., Bennett, M. L., Scholze, A. R., O'Keeffe, S., et al. (2014). An RNA-sequencing transcriptome and splicing database of glia, neurons, and vascular cells of the cerebral cortex. J. Neurosci. 34, 11929-11947. doi: 10.1523/jneurosci.1860-14.2014

Zhao, C., Fancy, S. P., ffrench-Constant, C., and Franklin, R. J. (2008). Osteopontin is extensively expressed by macrophages following CNS demyelination but has a redundant role in remyelination. Neurobiol. Dis. 31, 209-217. doi: 10.1016/j. nbd.2008.04.007
Conflict of Interest Statement: The authors declare that the research was conducted in the absence of any commercial or financial relationships that could be construed as a potential conflict of interest.

Copyright (c) 2018 Boardman, Ireland, Sullivan, Pataky, Fleiss, Gressens and Miron. This is an open-access article distributed under the terms of the Creative Commons Attribution License (CC BY). The use, distribution or reproduction in other forums is permitted, provided the original author(s) and the copyright owner(s) are credited and that the original publication in this journal is cited, in accordance with accepted academic practice. No use, distribution or reproduction is permitted which does not comply with these terms. 